\title{
Anxiety in patients with hysterical conversion symptoms
}

\author{
MALCOLM LADER AND NORMAN SARTORIUS
}

From the Institute of Psychiatry, Maudsley Hospital, London

In psychiatry, most diagnoses are descriptions of behaviour or of phenomena reported by the patient, whereas in somatic medicine a diagnosis usually includes the pathological process underlying a syndrome or a symptom. Consequently, when a group of conditions were delineated which appeared to be of somatic origin, yet for which no organic cause was apparent, it was not surprising that terms implying aetiology were used. The term 'hysteria' owes its derivation to the suggestion that the womb travels in the body and causes hysterical symptoms by settling in the brain. During the Middle Ages possession by demons was regarded as the cause of such symptoms and the sufferers were in peril of being denounced as witches. Later, the possible connexion between sexual emotion and hysteria was recognized, but in the nineteenth century such views were discounted in the prevailing medical climate of the time, which viewed all abnormal mental phenomena in terms of diseased brain structure. Charcot and Janet re-established hysteria as an essentially psychological illness and, more recently, new aetiological assumptions led to these conditions being labelled 'conversions' or 'conversion reactions'. In these theories, it is postulated that the 'psychic energy' associated with unacceptable urges can be 'converted' into somatic symptoms which allow the release of repressed affects, and the ego is protected from experiencing them and the resultant anxiety. In a similar way other neurotic symptoms are supposed to alternate with anxiety (Fenichel, 1945). In the course of time this model has been so widely adopted that it encompasses the wide range of psychosomatic illnesses, and even somatic diseases with clearly defined organic causes-for example, malignancies - have been partly or wholly explained along these lines (Deutsch, 1959).

However plausible this mechanism of conversion may sound, the evidence for it resides mainly in $a$ posteriori explanations and in anecdotal clinical material. Ziegler and Imboden (1962) survey the literature on the subject and state that the '... "defense mechanism" theory of conversion symptoms might actually be challenged on logical grounds since, except for abundant inferential clinical data, no음 experimental evidence or "proof" has heretofore $\frac{\bar{c}}{\bar{c}}$ been produced'. Similarly, the concept of 'conversion $\frac{\sigma}{\sigma}$ of psychic energy' has been criticized as having no $\varrho$ biological foundation (Chodoff and Lyons, 1958).

We have set out to test this psychodynamic $\overrightarrow{0}$ hypothesis experimentally. According to psychoanalytical views, conversion symptoms are instru- $\vec{\omega}$ mental for the relief of anxiety. They serve a purpose? in diminishing anxiety and protect the subject from experiencing it. Thus, Freud (1948) states categoric- $\omega$ ally: 'There are plenty of neuroses which exhibit $\vec{\sim}$ no anxiety whatever. True conversion-hysteria is one $\mathrm{cr}$ of these. Even in its most severe symptoms no a $\bar{\phi}-\overrightarrow{0}$ mixture of anxiety is found.' From such a standpoirf, it would be logical to expect that the anxiety leves in hysterics with developed conversion symptonos would be lower than anxiety levels in patients withy? anxiety and phobic states in whom 'free-floatines anxiety was apparent.

Methodologically there are at least two other was of examining the inter-relation of conversion symp- $\vec{p}$ toms and anxiety. Firstly, one could estimate the level of anxiety in subjects deemed likely to develop hysterical phenomena and re-examine them after such symptoms emerged: this was hardly feasible for obvious reasons. The second possibility was to $\frac{\circ}{\square}$ assess anxiety in patients with conversion symptoms $\stackrel{\circ}{\Rightarrow}$ before treatment and to repeat the measurements after the symptoms had subsided. This would have entailed considerable practical and theoretical difficulties. Firstly, symptoms might be slow to resolve or even be intractable and, furthermore, the outcome of such an investigation would remain? equivocal. Thus, diminution of anxiety after the conversion symptom disappeared might be interpreted in different ways: that a primary decrease ino anxiety enabled the symptom to subside; that the removal of the symptom diminished anxiety음 secondary to it; that the lessening of anxiety, $D$ although a result of treatment, occurred indepen-을. dently of the removal of the conversion symptom. Conversely, no change in anxiety levels might mean that the symptom and the anxiety were independent 0 
manifestations of neurosis; or that the therapy had lessened neurotic processes sufficiently to abolish the 'excess' anxiety previously 'converted' into an hysterical symptom, while leaving the overt anxiety undiminished. An increase of anxiety parallel to the disappearance of the symptom could be interpreted as 'overfilling' of the psychological channel or as an independent change in the level of anxiety.

As these two experimental designs appeared impracticable we resorted to examining the simple hypothesis formulated as follows:

'Patients with hysterical conversion symptoms have lower levels of anxiety than an agecomparable group of patients with anxiety states.' Measurements of anxiety used included self-ratings of the patients, clinical assessments by psychiatrists, and psychophysiological parameters-namely, the palmar skin conductance and its response (GSR). In previous experiments, the validity of these autonomic variables as concomitants of anxiety has been established (Lader and Wing, 1966).

\section{METHODS}

PATIENTS The patients studied suffered from hysterical conversion phenomena - that is, they complained of, or displayed, symptoms and signs usually of an apparently neurological nature for which no organic cause had been found after intensive somatic investigation. A consultant psychiatrist made the diagnosis of conversion hysteria independently from one of us. All but one were in-patients. The main clinical features of the 10 patients are displayed in Table $\mathrm{I}$. The mean age of the group was 29.2 years (S.D. 12·3).

The skin conductance data of these patients were compared with two other groups of subjects studied previously under identical conditions (Lader, 1967): (a) 71 patients with anxiety states, agoraphobia, or social phobias (mean age 32.0 yr; S.D. 8.75; 37 males), and (b) 75 normal controls (mean age $30.0 \mathrm{yr}$; S.D. 9.6; 35 males).

PROCEDURE Consultant psychiatrists at the Maudsley Hospital referred patients they deemed suitable for the study. The patients were intensively interviewed and those fulfilling the diagnostic criteria were invited to participate. The research purpose and voluntary nature of the investigations were emphasized. No patient refused to take part. Patients on drugs had their medications stopped for $\mathbf{4 8}$ hours in the case of sedatives, and for two weeks in the case of phenothiazines. The rating scales and inventories were administered and the standard physiological test carried out.

PHYSIOLOGICAL MEASURES The palmar skin conductance (sweat gland activity) was recorded during a standardized stimulation procedure using techniques detailed elsewhere (Lader and Wing, 1966). After 12 minutes at rest, 20 auditory stimuli were presented automatically, the interval between stimuli varying from 45 to 80 seconds. Each stimulus was a $1 \mathrm{kHz}$ tone of 1 second's duration and $100 \mathrm{db}$ intensity.

Two variables only will be presented here, namely 'habituation' and 'level of arousal'. Firstly, the rate of decrement of the responses (GSRs) of the patient to the stimuli was calculated using statistical regression techniques. The scores obtained were 'reflected' (sign reversed) so that the more positive the score, the more rapid the habituation. (It may be noted that in reports of earlier work the scores were not reflected.) This variable relates to the rate of 'habituation' of the patient. Secondly, the numbers of spontaneous fluctuations in the skin conductance trace were totalled for eight periods of 40 seconds during the last quarter of the recording session. These fluctuations are small oscillations in the tracing which occur in the absence of any detectable external stimuli: this variable is an estimate of the level of arousal'.

RATING SCALES (a) Overt anxiety The patient's behaviour was observed by the experimenter as the electrodes were being applied and the experimental procedure explained. The degree of overt anxiety was rated on a seven-point scale ranging from 0 -no anxiety apparent, to 3-moderate anxiety, on to 6-extreme anxiety.

(b) Self-ratings of anxiety The patient was presented with a graphic rating scale consisting of three horizontal $10 \mathrm{~cm}$ lines labelled 'nil' at the left-hand end and 'very severe' at the other. She was asked to estimate her

TABLE I

CLINICAL FEATURES OF PATIENTS

\begin{tabular}{|c|c|c|c|c|c|c|}
\hline $\operatorname{Sex}$ & Age & $\begin{array}{l}\text { Marital } \\
\text { status }\end{array}$ & Conversion symptoms & $\begin{array}{l}\text { Duration } \\
\text { (months) }\end{array}$ & Course & Precipitating factors \\
\hline $\mathbf{F}$ & 22 & $\mathbf{S}$ & Dissociative state, aphonia & 80 & Worsening & Birth of brother \\
\hline $\mathbf{F}$ & 21 & $\mathbf{S}$ & Weakness of hand & 40 & Worsening & None discernible \\
\hline $\mathbf{F}$ & 37 & $\mathbf{M}$ & Astasia-abasia & 6 & Steady & Car accident \\
\hline $\mathbf{F}$ & 18 & $\mathbf{S}$ & Fits, tremor of hand, ataxia & 35 & Fluctuating & None discernible \\
\hline $\mathbf{F}$ & 50 & $\mathbf{M}$ & $\begin{array}{l}\text { Ataxia, widespread tremor, } \\
\text { blurring of vision }\end{array}$ & 25 & Steady & Death of mother and friend \\
\hline $\mathbf{F}$ & 21 & $\mathbf{S}$ & Ataxia & 18 & Fluctuating & Failure in college \\
\hline $\mathbf{F}$ & 43 & $\mathbf{S}$ & Astasia-abasia & 250 & Steady & Death of father and brother \\
\hline $\mathbf{M}$ & 41 & $\mathbf{M}$ & Amnesia & 3 & Improving & Pressing debts \\
\hline $\mathbf{F}$ & 18 & $\mathbf{S}$ & Mutism & 11 & Worsening & Minor car accident \\
\hline $\mathbf{M}$ & 21 & $\mathbf{S}$ & Paralysis and anaesthesia of & $1 \frac{1}{2}$ & Improving & Jilted by fiancée, loss of job \\
\hline
\end{tabular}


anxiety levels (a) before her present symptoms, (b) after the onset of her symptoms, and (c) at the present time, by making appropriate marks on the lines. These were measured to the nearest $\mathrm{mm}$ from the left.

(c) Semantic differential scales Rating scales based on the techniques of Osgood, Suci, and Tannenbaum (1957) and Marks (1965) were administered. The patients were given two sets of five seven-point scales on which they were asked to rate first themselves and then the 'man-inthe-street' - that is, the population 'norm'. The scales from left to right in order were: 'tense-relaxed', 'goodbad', 'unpleasant-pleasant', 'calm-anxious' and 'ill-well'. (d) Eysenck personality inventory This, the successor to the Maudsley Personality Inventory, yields scores of 'Neuroticism' and 'Extroversion' (Eysenck and Eysenck, 1964). It includes a 'Lie-Scale': as one patient scored more than the permissible number on this scale, the analyses for these scores were reduced to nine patients. The $B$ form of the inventory was used.

STATISTICAL ANALYSes Parametric statistics were used wherever possible. Paucity of evaluative intervals as in the semantic differential scales was not regarded as a contraindication to the use of parametric statistics, providing the distribution of the data did not depart grossly from normal.

\section{RESULTS OF PHYSIOLOGICAL MEASURES}

HABITUATION RATE The mean value for the 10 hysterics was -4 (S.D. 14). The negative sign indicates that there was a tendency, albeit nonsignificant, for the hysteric patients to increase the size of their responses as the stimuli were repeated. This mean value was compared in an analysis of variance with that for the 71 anxiety and phobic state patients $(+33 \pm 29)$ and with that for the 75 normal controls $(+72 \pm 36)$. The F-ratio was 41.81 (2, 153 d.f.; $P<0.001)$. The means of the two patient groups were significantly different ( $\mathrm{t}=3.38 ; P<0.001)$ as were the means of the anxiety-phobic patients and the normals $(\mathrm{t}=7 \cdot 34$; $P<0.001)$.

Thus it appeared that the hysteric patients showed no tendency to habituate; the anxiety-phobic patients had significantly higher rates, but were themselves slower than the normals.

SPONTANEOUS FLUCTUATIONS The means and standard deviations for the hysteric, anxiety-phobic, and normal groups were $59 \pm 10,35 \pm 8$, and $8 \pm 7$ respectively (F-ratio $=65.31 ; 2,153$ d.f.; $\boldsymbol{P}<0.001)$. Again, the three groups were distinguishable from each other; hysteric versus anxiety-phobic groups, $\mathrm{t}=4.15 ; P<0.001$; anxiety-phobic versus normal groups, $\mathrm{t}=9 \cdot 30 ; P<0.001$.

Consequently, the hysterics showed more physiological 'arousal' than the anxious patients who, in turn, were more active than the control subjects.

\section{RESULTS OF RATING SCALES}

OVERT ANXIETY There was a significant difference between the groups of patients' mean ratings on the 0 to 6 scale, which were 2.00 for the hysterics and 3.35 for the anxiety and phobic states $(\mathrm{t}=2.53$; $\boldsymbol{P}<0.02$ ). The correlation for the hysteric patients between overt anxiety ratings and spontaneous fluctuations was $+0.76(P=0.01)$-that is, frequent fluctuations were associated with much overt anxiety. The corresponding correlation for the 71 anxiety-phobic patients was $+0.58(P<0.001)$.

SELF-RATINGS OF ANXIETY The hysteric patients' retrospective ratings of anxiety before the onset of the current symptoms averaged 4.2 on the $10.0 \mathrm{~cm}$ line. Their mean rating of anxiety level once the symptom started was 8.0 and at the time of rating 8.5. There were significant differences between the ratings before and with the symptom $(\mathrm{t}=3.77$; $\boldsymbol{P}<0.005$ ) and between the ratings before the symptom and at the time of rating $(\mathrm{t}=4.25$; $\boldsymbol{P}<0.001)$. There was a significantly positive correlation between the self-rating of anxiety at the time of rating and the number of spontaneount fluctuations $(r=+0.70 ; P<0.02)$; this supports the validity of the autonomic variable as a core용 comitant of anxiety.

The mean self-rating of anxiety for the time rating for the 71 anxious and phobic patients was $\frac{0}{0}$ 6.6. This was significantly less than the value of $8: \frac{\mathbb{Q}}{\square}$ for the hysterics $(\mathrm{t}=3.60 ; P<0.001)$.

SEMANTIC DIFFERENTIAL SCALES The mean values for $\infty$ each of the scales for the hysterical patients' rating of themselves and the 'man-in-the-street' are shown in Fig. 1. It can be seen that the patients rate themselves considerably more 'tense', 'anxious', and 'ill' than they rate the 'man-in-the-street', whereas they regard themselves as about equally 'bad' and $\overrightarrow{\vec{F}}$ 'unpleasant'.

An analysis of variance was carried out for all the data (Table II). It can be seen that the scales $\times$ object of rating (patient or 'man-in-the-street') $(\mathrm{S} \times \mathbf{R})$ interaction is significant as Fig. 1 would suggest. Further analysis showed that, in general, the patients were rating themselves significantly more 'anxious', more 'tense', and more 'ill' than the 'man-in-the-street'. In the patient's rating of $\frac{0}{3}$ themselves, 'tense' and 'anxious' were accorded significantly higher values than 'ill', which was itself significantly higher than 'bad' and 'unpleasant'. 궁 This may be contrasted with the patient's ratings of the 'man-in-the-street', wherein the only significant $N$ contrasts are that 'calm' and 'well' are rated above $N$ 'good'. 


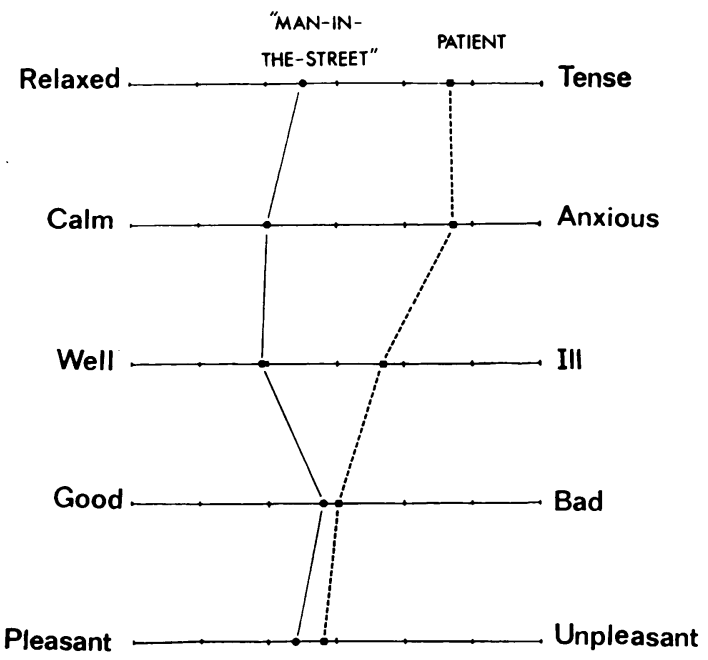

FIG. 1. Mean ratings of the 10 patients with hysterical conversion symptoms.

TABLE II

ANALYSIS OF VARIANCE FOR SEMANTIC DIFFERENTIAL SCALES

\begin{tabular}{|c|c|c|c|c|c|}
\hline $\begin{array}{l}\text { Sources of } \\
\text { variance }\end{array}$ & Varianc & $\begin{array}{l}\text { Degrees } \\
\text { of } \\
\text { freedom }\end{array}$ & $\begin{array}{l}\text { Mean } \\
\text { variance }\end{array}$ & $\begin{array}{l}\text { Variance } \\
\text { ratio }\end{array}$ & $\begin{array}{l}\text { Significance } \\
\text { level }\end{array}$ \\
\hline $\begin{array}{l}\text { Patients (P) } \\
\text { Scales (S) } \\
\text { Rating-object (R) } \\
\mathbf{P} \times \mathbf{S} \\
\mathbf{P} \times \mathbf{R} \\
\mathbf{S} \times \mathbf{R} \\
\mathbf{P} \times \mathbf{S} \times \mathbf{R}\end{array}$ & $\begin{array}{l}20 \cdot 8 \\
13 \cdot 6 \\
53 \cdot 2 \\
90 \cdot 3 \\
24 \cdot 7 \\
24 \cdot 6 \\
23 \cdot 5\end{array}$ & $\begin{array}{r}9 \\
4 \\
1 \\
36 \\
9 \\
4 \\
36\end{array}$ & $\begin{array}{r}2 \cdot 31 \\
3 \cdot 40 \\
53 \cdot 20 \\
2 \cdot 51 \\
2 \cdot 74 \\
6 \cdot 15 \\
0 \cdot 65\end{array}$ & $\left.\begin{array}{r}3 \cdot 55 \\
5 \cdot 23 \\
81 \cdot 84 \\
3 \cdot 87 \\
4 \cdot 22 \\
9 \cdot 47\end{array}\right\}$ & $\begin{array}{l}\text { interactions } \\
\text { significant } \\
<0.001 \\
<0.001 \\
<0.001\end{array}$ \\
\hline Total & $250 \cdot 7$ & 99 & & & \\
\hline
\end{tabular}

EYSENCK PERSONALITY INVENTORY For the B scale used, the mean Neuroticism score was 18 and the mean Extroversion score was 8. In the Manual of the Inventory, mean Neuroticism scores for scale B are given as 10.523 for normals, 16.491 for anxiety neurotics, and 15.768 for hysterics. The corresponding mean scores for the Extroversion scale are $14 \cdot 148,11 \cdot 241$, and $12 \cdot 791$ respectively. Thus the patients in the present study tend to have higher neuroticism and lower extroversion scores than both normals and anxiety states.

\section{DISCUSSION}

Chodoff and Lyons (1958) assert "that "hysteria" is currently used in at least 5 senses: 1 . a pattern of behavior habitually exhibited by certain indivi- duals who are said to be hysterical personalities or hysterical characters; 2 . a particular kind of psychosomatic symptomatology called conversion hysteria or conversion reaction; 3 . a psychoneurotic disorder characterized by phobias and/or certain anxiety manifestations - called anxiety hysteria; 4 . a particular psychopathological pattern; 5. a term of opprobrium.' The definition of patients in this study comes closest to the second category. We have examined patients in whom the diagnosis of conversion hysteria was made independently by two psychiatrists and who displayed signs of, or complained of symptoms of, apparent neurological deficit for which no organic cause had been found after intensive investigations. The symptoms of our patients were in all cases 'classical' of hysteria and the age and sex distributions of our patients were similar to those of other groups of patients with hysterical conversion symptoms (Purtell, Robins, and Cohen, 1951; Chodoff and Lyons, 1958; Gatfield and Guze, 1962; Ziegler and Imboden, 1962; Ziegler, Imboden, and Rogers, 1963; Lewis and Berman, 1965). A precipitating factor was present in all but two of our patients. Patients falling within our criteria were uncommon: in spite of full collaboration from the hospital medical and nursing staff, it took 15 months to study 10 patients.

Although only 10 patients with conversion symptoms have so far been studied, the results are consistent. Patients with conversion symptoms showed significantly more autonomic activity than the group of anxiety patients of similar age distribution. In previous work (Lader, 1967), it was shown that the anxiety-phobic patients did not differ amongst their diagnostic sub-categories with regard to the autonomic variables, so that the difference between the hysterical patients and the patients with anxiety or phobic states is not attributable to the 'dilution' of anxious patients with phobic patients who are not anxious at the time of testing. In fact, all the patients studied manifested some overt anxiety at the time. Nor were sex differences apparent in the data of the previous work so that the preponderance of female patients in the present study could not account for the results.

The autonomic measures used in the present study are generally taken to reflect the 'level of arousal' of the subject (Duffy 1962; Lader and Wing, 1966; Lader 1968). Consequently, patients with conversion symptoms are even more 'over-aroused' than patients with anxiety states. Indeed, the skin resistance tracings obtained in three of the hysterics resembled those seen previously during panic attacks in anxious patients. The high self-ratings of anxiety suggest that the over-arousal is accompanied by the affect of anxiety; also significant correlations were 
found between overt anxiety and spontaneous fluctuations (the index of arousal level) within the group of hysterics and within the group of anxious patients. If the relationship between these two measures were similar for each group, overt anxiety should have been higher in the hysterics pari passu with the increased arousal level. As this expectation was not fulfilled-overt anxiety being significantly lower-it appears that hysterical patients, while being greatly over-aroused and reporting excessive feelings, do not manifest commensurate overt anxiety. In other words, they appear less anxious than they claim and less 'over-aroused' than their autonomic measures would indicate. It must be emphasized that this phenomenon is distinct from that alleged to form the basis of 'belle indifference' in which the patient putatively shows little concern regarding her gross, disabling symptoms. Doubt has been cast on the validity of 'belle indifference' (Lewis and Berman, 1965) and all our patients displayed much concern for their plight.

The ratings of the semantic differential scales provided results of interest from two standpoints: firstly, they were consistent with the self-ratings of anxiety as the patients rated themselves as significantly more anxious, tense, and ill than the 'manin-the-street'; secondly, the patients regarded themselves as more anxious and tense than ill. The latter would suggest that the patients are acutely aware of their anxiety, which they regard as relatively greater than their degree of illness. Again, this finding is inconsistent with the notion of 'belle indifference' but fits in with the observations of Ziegler and his colleagues $(1962,1963)$ who found that among their patients with hysterical symptoms there was an appreciable number with features of neurotic anxiety, and with Lewis and Berman (1965) who noted anxiety reactions in 10 of their 57 patients with hysterical conversion symptoms.

Our hypothesis, that patients with conversion symptoms would possess lower anxiety levels than patients with anxiety neurosis, was not upheld. The 10 patients had mean levels of arousal and self-ratings of anxiety higher than anxious patients. Consequently, if 'conversion' is occurring, it is either a very imperfect mechanism or the preconversion arousal levels were astronomically high. The patients regarded themselves as less anxious before the symptom appeared than with it, although such ratings suffer the drawback of retrospection. Thus the 'conversion' may even leave the patient more overtly anxious. It is premature to speculate on the neurophysiological process involved while the anatomical and physiological substrates of anxiety remain unknown.

As indicated in Table I, the patients in our study were heterogeneous clinically; the physiological and $\bar{z}$ rating-scale data showed much more uniformity. $\stackrel{\mathbb{D}}{\stackrel{D}{\circ}}$ The number of patients studied was small, but such findings are more consistent with the viewpoint $\stackrel{\leftrightarrow}{\subseteq}$ that hysteria is a type of reaction rather than a distinct nosological or disease entity.

This study represents one way of examining psychodynamic formulations experimentally but many other possible approaches exist. We hope $\stackrel{2}{\gtrless}$ that more attempts will be forthcoming in the future, as the testing of such psychodynamic hypotheses $\stackrel{\vec{\sim}}{\rightarrow}$ using scientific methods is long overdue.

\section{SUMMARY}

Based on psychodynamic formulations, the hypothesis that patients with hysterical conversion \& symptoms would be less anxious than patients with. anxiety states was examined experimentally. Ten $\overrightarrow{\vec{\omega}}$ patients with conversion symptoms were investigated $\stackrel{\sigma}{\omega}$ using psychometric and physiological methods and $\overline{\bar{z}}$ compared with 71 patients with anxiety and phobic states, and 75 normal control subjects. The $\underset{\omega}{\omega}$ hysterical patients had significantly higher autonomic ir activity ('arousal') and rated themselves significant 8 is more anxious than the anxious-phobic patient The hypothesis, accordingly, was not upheld.

We are grateful to Professor Michael Shepherd fer invaluable help and advice during the course of th\$ work. Our thanks are due to the consultants of t迎 Maudsley Hospital for allowing their patients to particif. pate in this study. We wish to acknowledge also th assistance of the British Council and of the Psychiatry $\infty$ Department of Zagreb University Medical School which enabled Dr. Sartorius to participate in this investigation at the Maudsley Hospital, London. The work was supported by the Medical Research Council of Great Britain.

\section{REFERENCES}

Chodoff, P., and Lyons, H. (1958). Hysteria, the hysterical personality and 'hysterical' conversion. Amer. J. Psychiat., 114, 734-740.

Deutsch, F. (1959). On the Mysterious Leap from the Mind to the Body: A Workshop Study on the Theory of Conversion. International $O$ Universities Press, New York.

Duffy, E. (1962). Activation and Behavior. Wiley, New York.

Eysenck, H. J., and Eysenck, S. B. G. (1964). Manual of the Eysenck Personality Inventory. University of London Press, London.

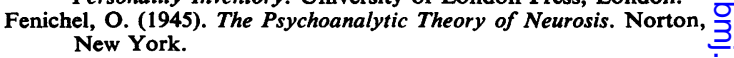

Freud, S. (1948). Inhibitions, Symptoms and Anxiety. Hogarth, London.

Gatfield, P. D., and Guze, S. B. (1962). Prognosis and differential $\supsetneq$ diagnosis of conversion reactions. Dis. nerv. Syst., 23, 623-631. O

Lader, M. H. (1967). Palmar skin conductance measures in anxiety and phobic states. J. psychosom. Res., 11, 271-281.

(1968). Psychophysiology of clinical anxiety. Hosp. Med., in press.

—, and Wing, L. (1966). Physiological Measures, Sedative Drugs, N and Morbid Anxiety. Oxford University Press, London.

Lewis, W. C., and Berman, M. (1965). Studies of conversion hysteria, $N$ 1. Operational study of diagnosis. Arch. gen. Psychiat., 13, 275-282. 
Marks, I. M. (1965). Patterns of Meaning in Psychiatric Patients. Oxford University Press, London.

Osgood, C. E., Suci, G. J., and Tannenbaum, P. H. (1957). The Measurement of Meaning. University of Illinois Press, Urbana, Illinois.

Purtell, J. J., Robins, E., and Cohen, M. E. (1951). Observations on clinical aspects of hysteria. A quantitative study of 50 hysteria patients and 156 control subjects. J. Amer. med. Ass., 146, 902-909.

Ziegler, F. J., and Imboden, J. B. (1962). Contemporary conversion reactions: II. A conceptual model. Arch. gen. Psychiat., 6, 279-287.

— - —, and Rodgers, D. A. (1963). Contemporary conversion reactions: III. Diagnostic considerations. J. Amer. med. Ass., 186, 307-311. 